\title{
Dominance rank and reproductive maturation in male rhesus macaques (Macaca mulatta)
}

\author{
F. B. Bercovitch \\ Caribbean Primate Research Center, University of Puerto Rico, Medical Sciences Campus, PO Box \\ 1053, Sabana Seca, PR 00952, USA and Wisconsin Regional Primate Research Center, University of \\ Wisconsin, 1223 Capitol Court, Madison, WI 53715, USA
}

\begin{abstract}
The timing of reproductive maturation in females has been linked to differences in dominance status and exposure to males, but less information is available regarding the effect of dominance rank and exposure to females on the pace of reproductive maturation in males. A twoyear study of a cohort of nine male rhesus macaques was undertaken to document potential social factors influencing variation in rates of reproductive maturation. The males lived in a large heterosexual group housed in a 0.3 ha outdoor enclosure. Every four weeks the focal subjects were isolated from the group to collect morphometric measurements and blood samples. The results revealed that dominance rank was not significantly correlated with average testosterone concentrations during the mating season. However, the highest ranking adolescent male had higher testosterone concentrations at a younger age, earlier in the mating season, and for a longer duration than did the lowest ranking male. Relative testicular weight was significantly correlated with dominance rank during the premating season, but not the postmating season, among adolescent males. The highest ranking adolescent male also engaged in more affiliative and sexual activity with nonkin, sexually receptive females than did lower ranking conspecifics. These patterns of development provide evidence that high dominance status accelerated reproductive maturation in male rhesus macaques.
\end{abstract}

\section{Introduction}

Subordinate social status hampers female reproductive maturation in many primate species (Abbott and Hearn, 1978; Epple and Katz, 1984; French et al., 1984; Ziegler et al., 1987, 1990; Bercovitch and Goy, 1990), whereas exposure to a male accelerates reproductive maturation among many female mammals (Vandenbergh, 1969a; Epple and Katz, 1980; Fadem, 1985; Ziegler et al., 1987; Izard, 1990; Stonerook and Harder, 1992). The consequences of low dominance rank and exposure to females for reproductive maturation among male mammals are less well documented. Subordinate male dwarf mongooses, Helogale parvula, have smaller testicles but the same testosterone concentrations as higher ranking conspecifics (Creel $e t$ al., 1992), whereas nonbreeding naked mole rats, Heterocephalus glaber, have suppressed testosterone concentrations in the absence of deficient spermatogenesis (Faulkes and Abbott, 1991). Unlike in females, suppressed endocrine concentrations in males are not necessarily associated with reduced gametogenetic function or reproductive success (Bercovitch and Goy, 1990).

Testosterone concentrations in male stumptail macaques, Macaca arctoides, were not correlated with dominance rank, sexual activity or aggressive behaviour, but the lowest ranking adult male had the lowest testosterone concentrations and received the greatest number of attacks (Niewenhuijsen et al.,

Received 16 October 1992
1987). Eaton and Resko (1974) reported that dominance rank was not correlated with testosterone concentrations or amount of aggressive activity in Japanese macaques, $M$. fuscata, but Dessi-Fulgheri et al. (1981) found that the highest ranking male Japanese macaque in their study had double the testosterone concentration of subordinate individuals. Dominance rank was not correlated with testosterone concentrations among adult male vervet monkeys, Cercopithecus aethiops, but rates of aggression were correlated with testosterone concentrations in dominant males (Steklis et al., 1985). Among adult male savanna baboons, Papio cynocephalus, in Kenya, testosterone concentrations were correlated with patterns of aggressive activity, not sexual behaviour, and dominance rank was correlated with levels of sexual activity, not with aggressive behaviour (Sapolsky, 1982). Alpha male lesser mouse lemurs, Microcebus murinus, living in heterosexual groups had testosterone concentrations comparable to those of isolated males, whereas the two or three subordinate males residing in the same heterosexual groups had testosterone concentrations about two-thirds that of the alpha male and comparable to each other (Perret, 1985). Testosterone concentrations climbed with elevations in dominance status and plummeted with declines in dominance status among male talapoin monkeys, Miopithecus talopoin (Eberhardt et al., 1980). In sum, androgenic effects on sexual and aggressive behaviour appear to be facilitatory, and social factors determine suppression or expression of these types of behaviour (see Dixson, 1980; Bernstein et al., 1983; Keverne, 1983; Bercovitch and Goy, 1990). Testosterone concentrations in male rhesus 
macaques are extremely responsive to social and sexual stimuli (Rose et al., 1972).

The potential link between dominance status and reproductive maturation among male primates has not been subject to very intense scrutiny. High dominance rank is associated with a younger age of testicular descent and an earlier onset of seasonal testosterone profiles in some macaques (Bercovitch and Goy, 1990). Among adolescent male bonnet macaques, $M$. radiata, testosterone titres correlated with both dominance rank (Glick, 1980), and levels of sexual activity (Glick, 1979).

A lengthy adolescent stage of development is a widespread characteristic of primates, and few studies have tracked developmental patterns on a longitudinal basis (Caine, 1986). The primary goal of this report is to document the role of social status on reproductive maturation in adolescent male rhesus macaques residing in a heterosexual group in a large outdoor enclosure. Reproductive maturation refers to changes in testicular mass and plasma testosterone concentrations that accompany the adolescent stage of development. The relative testicle size of rhesus macaques is one of the highest among primates, probably because of the multimale mating system coupled with seasonal patterns of sexual activity (Harcourt et al., 1981; Dixson, 1987). Two consequences of this pattern are paternal uncertainty and intense sperm competition (Bercovitch, 1992a). The effect of differential rates of reproductive maturation were examined in the context of mating system of the rhesus macaque to explore how dominance status can affect the onset of reproduction in male rhesus macaques.

\section{Materials and Methods}

\section{Animals}

Nine rhesus macaques were the focal subjects of this investigation. The males lived in a heterosexual social group (Group $\mathrm{M})$ in a tri-sectioned 0.3 ha outdoor enclosure housing approximately 150 monkeys at the Sabana Seca Field Station, Puerto Rico $\left(18^{\circ} 27^{\prime} \mathrm{N}, 66^{\circ} 12^{\prime} \mathrm{W}\right)$. The study site was located in a subtropical karst forest about $15 \mathrm{~km}$ west of San Juan. Water was available ad libitum and monkeys were fed daily with commercial monkey chow. Diet was occasionally supplemented with fresh fruit and the monkeys foraged on the grass within the enclosure. The entire social group had been translocated from Cayo Santiago to Sabana Seca in 1984 (Bercovitch and Lebrón, 1991), and the former site was inhabited by rhesus macaques since 1938 (Sade et al., 1985; Rawlins and Kessler, 1986). Reproductive seasonality is a characteristic of the Cayo Santiago rhesus macaques (Rawlins and Kessler, 1985). For unknown reasons, the median birth month has shifted among the Group $M$ rhesus macaques from February (1985) to December (1987) to July (1989).

About six months after birth, monkeys were tattooed with an identification number, but individual recognition was usually based upon general physiognomy. The alpha and omega males within the study cohort were born 6 days apart, with all of the adolescent subjects born between 30 October 1986 and 3 January 1987. The adolescent stage of development in rhesus macaques begins at about 3-3.5 years based upon commencement of production of fertile spermatozoa (Bercovitch and Goy, 1990). Data collected for this project were obtained between
January 1990 and December 1991, spanning the ages of 3-5 years among the study cohort.

\section{Sampling procedures}

Thirteen times per year, that is once every four weeks, the males were removed from their social group to collect blood samples and make morphometric measurements (Bercovitch, 1992b). Subject monkeys were encouraged to enter a small hallway $(140 \mathrm{~cm} \times 40 \mathrm{~cm} \times 56 \mathrm{~cm})$ connected to the large outdoor enclosure and leading to a gate that opens into an individual holding cage $(62 \mathrm{~cm} \times 48 \mathrm{~cm} \times 64 \mathrm{~cm})$. In addition to the nine adolescent male subjects, adult males were captured four times per year (January, April, July and October) to establish physiological and morphometric characteristics of adult males living in the same enclosure. Males are defined as adults after they reach 6 years of age, or the average age when skeletal maturation is complete (Turnquist and Kessler, 1989; Watts, 1990; Schwartz and Kemnitz, 1992). All monkeys were anaesthetized with approximately $10 \mathrm{mg}$ ketamine $\mathrm{HCl} \mathrm{kg}^{-1}$ (Ketaset ${ }^{\circledR}$ : Aveco, Fort Dodge, IA), and morphometric measurements and blood samples were usually collected before $10: 30 \mathrm{~h}$ from the subjects in a random order. This procedure is designed to control for diurnal rhythms characteristic of testosterone concentrations in rhesus macaques (Perachio et al., 1977; Rose et al., 1978; Chambers and Phoenix, 1981; Plant, 1981; Michael et al., 1984; Sehgal et al., 1986). On the afternoon of the same day, all males were released back into the large enclosure.

After immobilization, body weights were obtained using a battery operated scale that was accurate to the nearest $0.01 \mathrm{~kg}$. Length and width of testicles, as well as canine size, were measured using a sliding caliper accurate to $1.0 \mathrm{~mm}$. The scrotal sac was stretched to exclude the epididymis from measurement. Testicular volume (TV) in nonhuman primates is calculated using the formula for a regular ellipsoid (Abbott and Hearn, 1978; Dixson et al., 1980; Wickings and Nieschlag, 1980; Steiner and Bremner, 1981; Plant, 1985; Bercovitch, 1989; Marson et al., 1991):

$$
T V=\left(\pi W^{2} \times L\right) / 6
$$

where $W$ is the width of the testis and $L$ is the length of the testis. Testicular volume (TV) was calculated for both right and left testes and converted to weight using the regression equation $Y=1.534 x+5.736$ (Bercovitch and Rodriguez, 1993). Canine size was measured from the gingival margin to the tip of the canine on the maxilla of the right side. Blood samples were collected from the femoral vein in $13 \mathrm{ml} \mathrm{SST}$ Vacutainer collection tubes (Beckton-Dickson, Rutherford, NJ), centrifuged $(4470 \mathrm{~g}$ for $20 \mathrm{~min}$ ) within $2 \mathrm{~h}$ of collection, and the plasma frozen at $-20^{\circ} \mathrm{C}$.

Behavioural observations were obtained 5 days per week on an ad libitum basis (Altmann, 1974) while walking within all three sections of the enclosure. These behavioural observations are inadequate for evaluating rates of activities, but valid for deriving directionality and patterns of social interactions (Altmann, 1974; Bernstein, 1991). Lindburg (1983) has shown a good concordance among various estimates of male reproductive success in rhesus macaques using ad libitum data collected on male sexual activity. 
Table 1. Dominance hierarchy among the adolescent male rhesus macaques

\begin{tabular}{lrlllllllll}
\hline & \multicolumn{10}{c}{ Loser } \\
Rank & ID & 94 & 97 & 98 & 100 & 88 & 86 & 89 & 93 & 92 \\
\hline Winner & & & & & & & & & & \\
1 & 94 & - & 8 & 2 & 5 & 3 & 3 & 1 & 4 & 0 \\
2 & 97 & & - & 7 & 7 & 6 & 5 & 1 & 0 & 2 \\
3 & 98 & & & - & 2 & 1 & 1 & 0 & 2 & 0 \\
4 & 100 & & & & - & 1 & 1 & 0 & 0 & 1 \\
5.5 & 88 & & & & & -1 & 1 & 4 & 1 & 0 \\
5.5 & 86 & & & & & 1 & - & 1 & 1 & 0 \\
7 & 89 & & & & & & & - & 1 & 0 \\
8 & 93 & & & & & & & & - & 4 \\
9 & 92 & & & & & & & & & - \\
\hline
\end{tabular}

Animals are listed in descending dominance rank order. ID refers to the tattoo identification code and is not indicative of birth order. The values reported in each cell are the number of dyadic agonistic encounters recorded during the study when the participant in the row was ranked the 'winner' over the participant in the column.

Relative dominance ranks were derived for the nine adolescent males on the basis of all dyadic agonistic encounters recorded between the subjects. Agonistic behaviours included threats, chases, fights, avoidance of approaches, fear grimaces, and supplants over resources. The terms 'alpha' and 'omega' refer to relative rankings within the adolescent cohort of this study, unless otherwise noted.

\section{Testosterone radioimmunoassays}

Analysis of hormone concentrations was undertaken at the Wisconsin Regional Primate Research Center using procedures previously described in detail (Robinson et al., 1975). Plasma samples were extracted using diethyl ether and were then incubated with rabbit antitestosterone-BSA (Holly Hill Biomedicals, Hillsboro, OR), which crossreacts $30.8 \%$ with dihydrotestosterone, before radioimmunoassay. The final separation stage was accomplished with dextran-coated charcoal. Samples were assayed in duplicate, with the lower limit of detection $4.84 \mathrm{pg}$ $\mathrm{ml}^{-1}$. Recovery levels are about $96 \%$ for testosterone in the WRPRC Assay Laboratory. The intra- and interassay coefficients of variation were 2.2 and $6.8 \%$, respectively, for the high rhesus macaque male pool and 3.9 and $7.9 \%$, respectively, for the low pool.

\section{Statistical analysis}

Both parametric and nonparametric statistical tests were performed, with the level of significance set at $P<0.05$. For assessing the effects of dominance rank, data were transformed into linear rankings and the Spearman's correlation coefficient is reported. For comparisons using data obtained on a ratio scale, Pearson's product moment correlation coefficient is the statistic reported. The annual reproductive cycle was divided into two time points: premating (samples collected in October) and postmating (samples collected in April) periods (Bercovitch, 1992b). No reproductive activity was observed outside of the mating season. Reproductive seasonality among rhesus macaques is associated with alterations in testosterone concentrations (Robinson et al., 1975; Gordon et al., 1976; Sehgal et al., 1986; Bercovitch, 1992b), testicular size (Sade, 1964; Conaway and Sade, 1965), and sperm production (Zamboni et al., 1974; Sehgal et al., 1986). Comparisons of premating and postmating values were made using either independent or paired Student's $t$ test. Measures of central tendency report the mean \pm SEM. Analyses were undertaken using SYSTAT 4.0 (Wilkinson, 1988).

\section{Results}

\section{Dominance relationships}

A linear dominance hierarchy based upon dyadic agonistic interactions between adolescent males characterized the study cohort (Table 1). Male dominance rank was independent of age within the study cohort $\left(r_{\mathrm{S}}=-0.058, n=9, P>0.50\right)$.

\section{Dominance rank and testosterone concentrations}

Testosterone concentrations in adult males were over twice as high during the premating period as during the postmating period $\left(4.32 \pm 0.40 \mathrm{ng} \mathrm{ml}^{-1}\right.$ versus $1.80 \pm 0.10 \mathrm{ng} \mathrm{ml}^{-1}$; paired $t=6.834$, d.f. $=4, P<0.01$ ). Four-year-old males had premating season testosterone concentrations that were significantly lower than those of adult males $\left(2.29 \pm 0.44 \mathrm{ng} \mathrm{ml}^{-1}\right.$; $t=2.924$, d.f. $=10, P<0.02$ ), but significantly higher than their own testosterone concentrations when 3.5 years of age $\left(1.33 \pm 0.17 \mathrm{ng} \mathrm{ml}^{-1}\right.$; paired $t=2.352$, d.f. $\left.=8, P<0.05\right)$, indicating that seasonal testosterone profiles occurred before attainment of adult male testosterone concentrations. Five-yearold males had testosterone concentrations that were not significantly different from those of adult males during the premating season $\left(2.60 \pm 0.88 \mathrm{ng} \mathrm{ml}^{-1} ; t=0.805\right.$, d.f. $=11, P>0.40$ ).

Profiles of endocrine maturation were associated with dominance rank (Fig. 1), but rank effects were generally non-linear and most apparent in comparisons between the alpha and omega male. In the six-month mating season subsequent to 


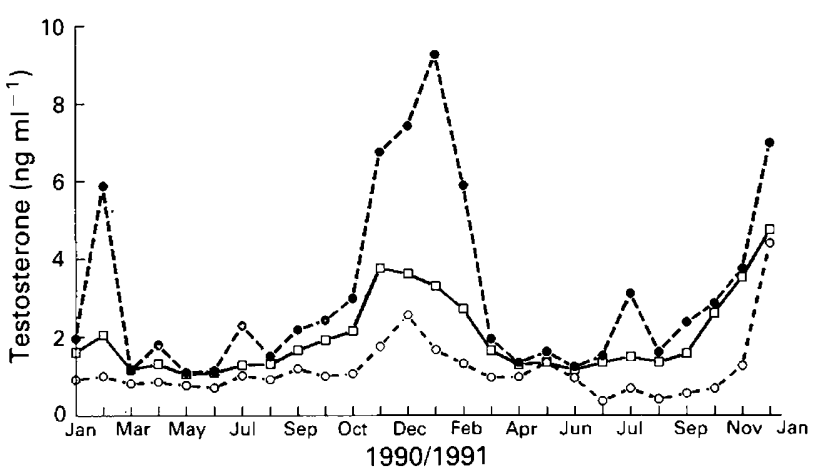

Fig. 1. The relationship between changes in testosterone concentration and age according to dominance rank among adolescent male rhesus macaques. All males were born in November-December 1986. For purposes of clarity, the standard error bars have been excluded from the figure. Average testosterone concentrations for the entire cohort ( $\square$ ) are compared with those of the alpha male (M94; ) and the omega male (M92; $\mathrm{O})$.

attainment of four years of age, the alpha male maintained the highest average monthly testosterone concentrations among his cohort $\left(5.79 \mathrm{ng} \mathrm{ml}^{-1}\right)$, whereas the omega male was characterized by the lowest average concentrations $\left(1.57 \mathrm{ng} \mathrm{ml}^{-1}\right)$. Of the twenty-six blood samples obtained per adolescent male between January 1990 and December 1991, the alpha male had testosterone concentrations in excess of $1.5 \mathrm{ng} \mathrm{ml}^{-1}$ on twenty occasions, whereas the omega male achieved this level only four times. Of the forty-four samples analysed from adult males, only one fell below this concentration.

At the onset of the mating season, dominance rank was significantly correlated with testosterone concentrations at both four and five years of age (Table 2). Testosterone concentrations during the premating period when four years of age were good predictors of levels at the premating period when five years of age $(r=0.940, n=8, P<0.001)$. However, dominance rank was not significantly correlated with average monthly testosterone concentrations during the mating season among the four-year-old males $\left(r_{\mathrm{S}}=0.571, n=9, P>0.10\right)$. The top third of the hierarchy had testosterone concentrations comparable to the bottom third of the hierarchy during the mating season $(t=1.063$, d.f. $=4, P>0.10)$. Using dates of birth and approximate duration of gestation to assess the time of conception revealed that $71 \%$ ( 24 of 34 ) of conceptions during this mating season occurred between December 1990 and January 1991. During this two month peak conception period, dominance rank among the adolescent males was not correlated with testosterone concentrations $\left(r_{\mathrm{S}}=0.379, n=9, P>0.20\right)$ and the top third and bottom third of the hierarchy maintained similar testosterone concentrations $(t=0.984$, d.f. $=4$, $P>0.50)$.

\section{Dominance rank and testicular development}

Estimated testicular weight of the adult male subjects during the premating period of October 1991 was $51.8 \pm 4.1 \mathrm{~g}(n=5)$, and the average testes:body weight ratio was 0.52 . The largest testicles $(61.4 \mathrm{~g})$ and the greatest relative testicle size $(0.63)$ characterized the highest ranking adult male in the troop, who was also the oldest male at 14.5 years.
The testicular weight of five-year-old males was $61 \%$ that of adult males $(31.8 \pm 5.1 \mathrm{~g} ; n=8)$ during the premating period, and their testes:body weight ratio $(0.38)$ was significantly less than that of adult males $(t=2.463$, d.f. $=11, P<0.05)$. Among adolescent male rhesus macaques, testicular weight was significantly correlated with body weight, but testosterone concentrations were independent of testicle size (see Table 2). Despite the close link between testicle size and body weight. dominant males had larger testicles, but were not heavier, than subordinate males (see Table 2). At five years of age, the alpha adolescent male weighed $11.3 \mathrm{~kg}$ and his testes weighed approximately $49 \mathrm{~g}$, while the omega adolescent male weighed $6.7 \mathrm{~kg}$ and his testes weighed about $11 \mathrm{~g}$. As a consequence, the relative testicular size of five-year-old males was a function of dominance rank (Fig. 2) during the premating period. Dominance status was not correlated with testes:body weight ratio among these same males during the postmating period $\left(r_{\mathrm{S}}=0.251, n=9, P>0.20\right)$.

Developmental patterns associated with canine growth proceeded at a pace independent of body growth. Size differences in canine length were virtually undetectable at four years of age, with seven of the nine males having right upper canine lengths of $4.0 \mathrm{~mm}$. By five years of age, canine size had increased 2.5 fold ( $1.1 \pm 0.2 \mathrm{~cm} ; n=8)$, but neither dominance rank $\left(r_{\mathrm{S}}=\right.$ $0.369, P>0.20)$ nor body weight $(r=0.432, P>0.20)$ were significantly correlated with canine length.

\section{Dominance rank and sexual activity}

During the 1990-1991 mating season, the three lowest ranking adolescent males were never observed copulating with females, whereas their three highest ranking conspecifics were recorded copulating with fifteen of forty sexually mature females. Backdating from birth date to probable conception date, based upon duration of gestation, indicated that the alpha male in this cohort copulated with eight females at about the suspected days of conception, while the beta male copulated with two. Because of data collection methods, rates of sexual activity cannot be ascertained, but the patterns noted are considered to reflect rank-related differences in sexual behaviour accurately. In general, the lower ranking males ranged on the periphery of the group, whereas their higher ranking counterparts engaged in much more social activity. In the 1990-1991 mating season, nonkin sexually mature females were never observed grooming the omega male, whereas the alpha male was groomed by twelve nonkin, sexually mature females.

\section{Discussion}

Some 3.5-year-old male rhesus macaques have systemic testosterone concentrations comparable to those of adult males during the mating season, but others do not achieve this concentration until 5.5 years of age (Bernstein et al., 1991). During this study, the highest ranking adolescent male had high testosterone concentrations at a younger age, earlier in the mating season, and for a longer duration than did the lowest ranking adolescent male. In accordance with the findings of Bernstein $e t$ al. (1991), dominance rank was not linearly correlated with 
Table 2. Correlation coefficients between morphometric measurements, testosterone concentrations, and dominance rank in adolescent male rhesus macaques

\begin{tabular}{lcccc}
\hline Characteristic & $3.5^{\mathrm{c}}$ & $4.0^{\mathrm{c}}$ & \multicolumn{4}{c}{ Age (years) } & \multicolumn{1}{c}{$5.0^{\mathrm{d}}$} \\
\hline Rank: testosterone $^{\mathrm{c}}$ & -0.628 & $-0.778^{*}$ & -0.603 & $-0.850^{*}$ \\
Rank: body weight $^{\mathrm{a}}$ & -0.251 & -0.536 & -0.370 & -0.491 \\
Rank: testes weight $^{\mathrm{a}}$ & -0.377 & $-0.720^{*}$ & $-0.703^{*}$ & $-0.790^{*}$ \\
Body weight: testes weight $^{\mathrm{b}}$ & $0.815^{* *}$ & $0.774^{*}$ & $0.752^{*}$ & $0.875^{* *}$ \\
Body weight: testosterone $^{\mathrm{b}}$ & 0.313 & 0.186 & -0.199 & 0.041 \\
Testes weight: testosterone $^{\mathrm{b}}$ & 0.280 & 0.329 & -0.054 & 0.316 \\
\hline
\end{tabular}

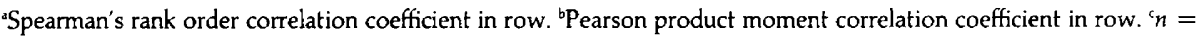
$9 ;{ }^{d} n=8 ;{ }^{*} P<0.05 ;{ }^{* *} P<0.01$. Significance levels refer to correlations between the two traits linked in each row. High ranking individuals are generally assigned the lowest numbers, so a negative correlation coefficient between dominance rank and a trait indicates that the trait is elevated in the dominant individuals. The correlation coefficients in each cell were obtained during the postmating periods of April 1990 (3.5 years) and 1991 (4.5 years) and the premating periods of October 1990 (4.0 years) and 1991 (5.0 years).

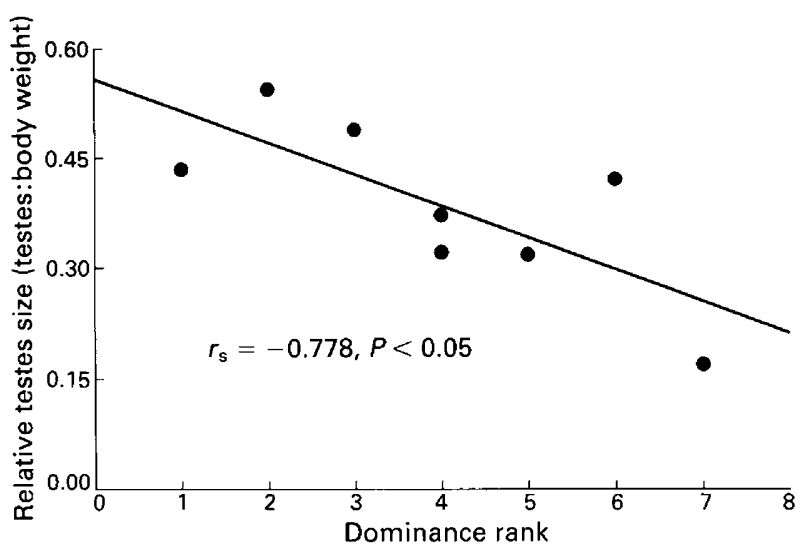

Fig. 2. The association between relative testicle size and dominance rank among five-year-old male rhesus macaques during the premating period. The highest ranking male within the cohort has been assigned the lowest number. Among the same males when four years of age, an identical pattern emerged $\left(r_{\mathrm{S}}=-0.703, n=9, P<0.05\right)$.

testosterone concentrations among adolescent males throughout the mating season, but the highest ranking male within a cohort had the greatest testosterone concentrations.

The impact of courtship activity on reproductive endocrinology among nonprimates has been well documented (see, for example, Lehrman, 1964; Harding, 1983; McComb, 1987), but the potential role of 'courtship' behaviour on male reproductive maturation among nonhuman primates has not been addressed. Circumstantial evidence indicates that proceptive activities of females can influence the timing of reproductive maturation among male primates. Testosterone concentrations and levels of sexual activity are higher among pubescent male rhesus macaques housed with three females compared with those of conspecifics of the same age housed with only a single female (Goy et al., 1992). During this study, both testosterone concentrations and the extent of sexual and affiliative behaviour with females were greater in the alpha adolescent male than in the omega adolescent male.
Exposing adult male rhesus macaques to oestrogenized females during the nonmating season results in an increase in testosterone concentrations (Vandenbergh, 1969b; Bernstein et al., 1977), and testosterone concentrations increase in male pigtail macaques, $M$. nemestrina, when a female is introduced into a group (Bernstein et al., 1978). Similarly, introduction of an oestrogen-primed long-tail macaque to peer groups of adolescent, or adult, males increases testosterone concentrations (Glick, 1984). Under conditions of rank instability, the male vervet monkey who engaged in the most affiliative behaviour with females emerged as the new alpha male in the group (Raleigh and McGuire, 1990). Chimpanzees, Pan troglodytes, that have higher testosterone concentrations are involved in more genital inspections (Nadler et al., 1987) than those with lower concentrations and the degree of sexual stimulation is correlated with testosterone concentrations among humans (Knussman et al., 1986). Given that intersexual courtship patterns prime reproductive hormones, and that visual and tactile exposure to females increases testosterone concentrations in many primate species, the testable prediction can be made that the timing of male reproductive maturation is a function of the degree of affiliative and sexual activity with females. The patterns of activity documented in the present investigation indicate that a synergistic effect between dominance status and intersexual social activity can determine the timing of reproductive maturation.

High testosterone concentrations could be a cause, or a consequence, of social conditions. Among male nonhuman primates, sexual activity is strongly suppressed following castration (Wilson and Vessey, 1968; Resko and Phoenix, 1971; Dixson, 1980; Schenk and Slob, 1986). However, sexual behaviour in males depends upon surpassing threshold concentrations of testosterone (Michael et al., 1984) and does not directly reflect absolute concentrations of testosterone. Glick (1980) found that the most sexually active adult male bonnet macaque had the lowest testosterone concentrations. Among rhesus macaques, annual monthly mean testosterone changes parallel annual mean monthly mount rates, but individual testosterone concentrations are not correlated with individual mount rates (Gordon et al., 1976). In both primates (Gordon et al., 1976; 
Rose et al., 1978; Bercovitch and Goy, 1990) and nonprimates (for example Spermophilus beecheyi, Holekamp and Talamantes, 1991), annual peaks in testosterone concentrations precede or coincide with the onset of the mating season. Keverne (1983) has reasoned that suppressed testosterone concentrations in subordinate male primates is unlikely to be the primary mechanism accounting for reduced sexual activity in these males.

Investigations of gonadectomized males has revealed that testosterone is unlikely to be the cause of differences among males in levels of aggressive behaviour. Prepubertally castrated males can fight and dominate intact males (Wilson and Vessey, 1968; Bernstein et al., 1979). At the Yerkes Regional Primate Research Center, wounding in male rhesus macaques is most frequent during the nonmating season (Ruehlmann et al., 1988), but testosterone is at its nadir during that time (Gordon et al., 1976). The degree to which aggressive activity influences access to female rhesus macaques has probably been exaggerated (see, for example, Berenstain and Wade, 1983). High ranking males disrupt the mount attempts of lower ranking males (Ruiz de Elvira and Herndon, 1986), but male aggression is more often directed at the female consort partner than at other males (Lindburg, 1971, 1983). Lindburg (1971) never observed males fighting for access to females during his field study of rhesus macaques in India and he noted that ". . . males did not compete for females; partner change was the prerogative of the female..."

In the present study, the alpha adolescent male had more sexual partners than did the omega adolescent male. The alpha male was a descendant of the highest ranking matriline in the troop, but this matriline had fewer members than the other two matrilines in Group M. Hence, the alpha male had fewer matrilineal kin in the troop, so the greater number of mating partners could be a byproduct of the number of potential nonkin available rather than an outcome of his status. However, this is unlikely because the beta male and omega male were from the same original matriline (the great-grandmother of the omega male was the sister of the great-great-grandmother of the beta male), but the beta male engaged in both affiliative and sexual activity with more females than did the omega male.

High ranking adolescent males had larger testicles than did lower ranking males, but rank effects on body weight and canine size were absent. In addition, four-year-old males had testicle weights that were about half those of adult males, while their canine lengths were only about $25 \%$ that of adult males (Bercovitch, unpublished). Rank-related differences in testicle size, but not canine size or body size, coupled with the more rapid developmental trajectory of gonads compared with canines, support the idea that sperm competition may be more important than aggressive competition as a determinant of reproduction in male rhesus macaques (Bercovitch, 1992a). Spermatozoa from pubertal chimpanzees are less motile than those from adult males (Marson et al., 1991), and efficiency of sperm production is lower among adolescent rhesus macaques than among adults (Amann et al., 1976), but adolescent male rhesus macaques living in large outdoor heterosexual groups have sired offspring when 3.5 to 4.0 years of age (Bernstein et al., 1991; Smith et al., 1992; Bercovitch, unpublished). If males cannot exclude other males from access to sexually receptive females, or if surreptitious copulations occur, then relatively large testicles can be advantageous (Popp and DeVore, 1979). DNA fingerprint analysis of free-ranging rhesus macaques has shown that furtive copulations have resulted in viable offspring (Berard et al., 1990). Covariation among traits such as dominance rank, relative testicle size, and sexual activity with females provide evidence that the age at onset of reproduction in male rhesus macaques is likely to depend upon social status.

In summary, dominance rank influences reproductive maturation in males, but the effect is nonlinear and most pronounced at both ends of the hierarchy. Higher ranking adolescent males have relatively large testicles compared with lower ranking conspecifics, a morphological partitioning of resources that can provide dominant males with an edge in sperm competition. One impetus priming accelerated sexual maturation in males could be increased levels of affiliative activity with females. Enhanced rates of social activity with females may stimulate reproductive maturation in males, as well as providing adolescent males with access to individuals that are essential for initiating their reproductive careers. However, the impact of rank-related differences in timing of reproductive maturation on the age at first reproduction among males is unknown owing to the paternal uncertainty that characterizes the mating system of rhesus macaques. Current analysis of sirehood based upon DNA fingerprint profiles (Bercovitch, unpublished) should provide the information required for linking reproductive maturation with reproductive success.

Assistance in data collection was provided by M. Lebrón; endocrine assays were performed by G. Scheffler and D. Wittwer; and capture of study subjects was under the supervision of H. S. Martinez. The manuscript has benefitted from critical comments provided by D. H. Abbott, I. S. Bernstein, S. M. Schwartz, and J. G. Vandenbergh. Research was funded by a grant from the H. F. Guggenheim Foundation, with supplementary support provided by NIH Grant RR03640 to the CPRC. This is publication No. 33-017 of the WRPRC.

\section{References}

Abbott DH and Hearn JP (1978) Physical, hormonal and behavioural aspects of sexual development in the marmoset monkey, Callithrix jaccus Journal of Reproduction and Fertility 53 155-166

Altmann J (1974) Observational study of behaviour: sampling methods Behaviour 49 227-267

Amann RP, Johnson L, Thompson DL, Jr and Pickett BW (1976) Daily spermatozoal production, epididymal spermatozoal reserves and transit time of spermatozoa through the epididymis of the rhesus monkey Biology of Reproduction 15 586-592

Berard JD, Schmidtke J and McGeehan L (1990) Male reproductive success in a free-ranging colony of rhesus macaques American Joumal of Primatology 20 173 (Abstract)

Bercovitch FB (1989) Body size, sperm competition, and determinants of reproductive success in male savanna baboons Evolution 43 1507-1521

Bercovitch FB (1992a) Sperm competition, reproductive tactics, and patemity in savanna baboons and rhesus macaques. In Paternity in Primates: Genetic Tests and Theories, pp 225-237 Eds RD Martin, AF Dixson and EJ Wickings. Karger, Basel

Bercovitch FB (1992b) Estradiol concentrations, fat deposits, and reproductive strategies in male rhesus macaques Hormones and Behavior 26 272-282

Bercovitch FB and Goy RW (1990) The socioendocrinology of reproductive development and reproductive success in macaques. In Socioendocrinology of Primate Reproduction, pp 59-93 Eds TE Ziegler and FB Bercovitch. Wiley-Liss, New York

Bercovitch FB and Lebrón MR (1991) Impact of artificial fissioning and social networks on levels of aggression and affiliation in primates Aggressive Behavior 17 17-25

Bercovitch FB and Rodriguez JF (1993) Testis size, epididymis weight, and sperm competition in rhesus macaques American Journal of Primatology 30 $163-168$ 
Berenstain L and Wade TD (1983) Intrasexual selection and male mating strategies in baboons and macaques International Joumal of Primatology 4 20I-235

Bernstein IS (1991) An empirical comparison of focal and ad libitum scoring with commentary on instantaneous scans, all occurrence and one-zero techniques Animal Behaviour 42 721-728

Bernstein IS, Rose RM and Gordon TP (1977) Behavioral and hormonal responses of male rhesus monkeys introduced to females in the breeding and nonbreeding season Animal Behaviour 25 609-614

Bernstein IS, Gordon TP, Rose RM and Peterson MS (1978) Influences of sexual and social stimuli upon circulating levels of testosterone in male pigtail macaques Behavioral Biology 24 400-404

Bernstein IS, Gordon TP and Peterson M (1979) Role behavior of an agonadal alpha-male rhesus monkey in a heterosexual group Folia Primatologica 32 263-267

Bernstein IS, Gordon TP and Rose RM (1983) The interaction of hormones, behavior, and social context in nonhuman primates. In Hormones and Aggressive Behavior, pp 535-56I Ed. BB Svare. Plenum Press, New York

Bernstein IS, Ruehlmann TE, Judge PG, Lindquist T and Weed JL (1991) Testosterone changes during the period of adolescence in male rhesus monkeys (Macaca mulatta) American Journal of Primatology 24 29-38

Caine NG (1986) Behavior during puberty and adolescence. In Comparative Primate Biology, Vol. 2A, pp 327-361 Eds G Mitchell and J Erwin. Alan R Liss, New York

Chambers KC and Phoenix CH (1981) Diurnal patterns of testosterone, dihydrotestosterone, estradiol, and cortisol in serum of rhesus males: relationship to sexual behavior in aging males Hormones and Behavior 15 416-426

Conaway CH and Sade DS (1965) The seasonal spermatogenic cycle in free-ranging rhesus monkeys Folia Primatologica 3 1-12

Creel S, Creel N, Wildt DE and Monfort SL (1992) Behavioural and endocrine mechanisms of reproductive suppression in Serengeti dwarf mongooses Animal Behaviour 43 231-245

Dessi-Fulgheri F, Messeri P and Lupo de Prisco C (1981) A study of testosterone, estradiol, cortisol and prolactin in a socially intact group of Japanese macaques Anthropologia Contemporanea 4 123-127

Dixson AF (1980) Androgens and aggressive behavior in primates: a review Aggressive Behavior 6 37-67

Dixson AF (1987) Observations on the evolution of the genitalia and copulatory behaviour in male primates Joumal of Zoology 213 423-443

Dixson AF, Gardner IS and Bonney RC (1980) Puberty in the male owl monkey (Aotus trivirgatus grisemembra): a study of physical and hormonal development International joumal of Primatology 1 129-139

Eaton GG and Resko JA (1974) Plasma testosterone and male dominance in a Japanese macaque (Macaca fuscata) troop compared with repeated measure of testosterone in laboratory males Hormones and Behavior 5 251-259

Eberhart JA, Keverne EB and Meller RE (1980) Social influences on plasma testosterone levels in male talapoin monkeys Hormones and Behavior 14 $247-266$

Epple G and Katz Y (1980) Social influences on first reproductive success and related behaviors in the saddle back tamarin (Saguinus fuscicollis, Callitrichidae) International Joumal of Primatology 1 171-182

Epple G and Katz Y (1984) Social influences on estrogen excretion and ovarian cyclicity in saddle back tamarins (Saguinus fuscicollis) American joumal of Primatology 6 215-227

Fadem BH (1985) Evidence for the activation of female reproduction by males in a marsupial, the gray short-tailed opposum (Monodelphis domestica) Biology of Reproduction 33 112-116

Faulkes CG and Abbott DH (1991) Social control of reproduction in breeding and non-breeding male naked mole-rats (Heterocephalus glaber) Journal of Reproduction and Fertility 93 427-435

French JA, Abbott DH and Snowdon CT (1984) The effect of social environment on estrogen excretion, scent marking, and sociosexual behavior in tamarins (Saguinus oedipus) American Journal of Primatology 6 155-167

Glick BB (1979) Testicular size, testosterone level, and body weight in male Macaca radiata: maturational and seasonal effects Folia Primatologica 32 268-289

Glick BB (1980) Ontogenetic and psychobiological aspects of the mating activities of male Macaca radiata. In The Macaques, pp 345-369 Ed. DG Lindburg. Van Nostrand Reinhold, New York

Glick BB (1984) Male endocrine responses to females: effects of social cues in cynomolgus macaques American Joumal of Primatology 6 229-239
Gordon TP, Rose RM and Bernstein IS (1976) Seasonal rhythm in plasma testosterone levels in the rhesus monkey (Macaca mulatta): a three year study Hormones and Behavior $7229-243$

Goy RW, Neff DA, Sladky KK and Davis GA (1992) Effects of group composition on the expression of pubertal characteristics of male rhesus monkeys. In Sex Matters, pp 89-92 Ed. W Bezemer. Elsevier, New York

Harcourt AH, Harvey PH, Larson SG and Short RV (1981) Testis weight, body weight and breeding system in primates Nature $29355-57$

Harding CF (1983) Hormonal influences on avian aggressive behavior. In Hormones and Aggressive Behavior, pp 435-467 Ed. BB Svare. Plenum Press, New York

Holekamp KE and Talamantes F (1991) Seasonal variation in circulating testosterone and oestrogens of wild-caught California ground squirrels (Spermophilus beecheyi) Journal of Reproduction and Fertility 93 415-425

Izard MK (1990) Social influences on the reproductive success and reproductive endocrinology of prosimian primates. In Socioendocrinology of Primate Reproduction, pp 159-186 Eds TE Ziegler and FB Bercovitch. Wiley-Liss, New York

Keverne EB (1983) Endocrine determinants and constraints on sexual behaviour in monkeys. In Mate Choice, pp 407-420 Ed. PPG Bateson. Cambridge University Press, Cambridge

Knussmann R, Christiansen K and Couwenbergs C (1986) Relations between sex hormone levels and sexual behavior in men Archives of Sexual Behavior 15 429-445

Lehrmann DS (1964) The reproductive behavior of ring doves Scientific American $21148-54$

Lindburg DG (1971) The rhesus monkey in North India: an ecological and behavioral study. In Primate Behavior, pp 1-106 Ed. LA Rosenblum. Academic Press, New York

Lindburg DG (1983) Mating behavior and estrus in the Indian rhesus monkey. In Perspectives in Primate Biology, pp 45-61 Ed. PK Seth. Today \& Tomorrow's Printers \& Publishers, New Delhi

McComb K (1987) Roaring by red deer stags advances the date of oestrus in hinds Nature $330648-649$

Marson J, Meuris S, Cooper RW and Jouannet P (1991) Puberty in the male chimpanzee: progressive maturation of semen characteristics Biology of Reproduction 44 448-455

Michael RP, Zumpe D and Bonsall RW (1984) Sexual behavior correlates with the diurnal plasma testosterone range in intact male rhesus monkeys Biology of Reproduction $30652-657$

Nadler RD, Wallis L, Roth-Meyer C, Cooper R and Baulieu EE (1987) Hormones and behavior of prepubertal and peripubertal chimpanzees Hormones and Behavior 21 118-131

Nieuwenhuijsen K, de Neef KJ, van der Werff ten Bosch JJ and Slob AK (1987) Testosterone, testis size, seasonality, and behavior in group-living stumptail macaques (Macaca arctoides) Hormones and Behavior 21 153-169

Perachio AA, Alexander M, Marr LD and Collins DC (1977) Diurnal variations of serum testosterone levels in intact and gonadectomized male and female rhesus monkeys Steroids $2921-33$

Perret M (1985) Influence of social factors on seasonal variations in plasma testosterone levels of Microcebus murinus Zeitschrift fur Tierpsychology 69 $265-280$

Plant TM (1981) Time courses of concentrations of circulating gonadotropin, prolactin, testosterone, and cortisol in adult male rhesus monkeys (Macaca mulatta) throughout the $24 \mathrm{~h}$ light-dark cycle Biology of Reproduction 25 244-252

Plant TM (1985) A study of the role of the postnatal testes in determining the ontogeny of gonadotropin secretion in the male rhesus monkey (Macaca mulatta) Endocrinology 116 1341-1350

Popp JL and DeVore I (1979) Aggressive competition and social dominance theory: synopsis. In The Great Apes, pp 317-338 Eds DA Hamburg and ER McCown. Benjamin Cummings, Menlo Park

Raleigh MJ and McGuire MT (1990) Social influences on endocrine function in male vervet monkeys. In Socioendocrinology of Primate Reproduction, pp 95-111 Eds TE Ziegler and FB Bercovitch. Wiley-Liss, New York

Rawlins RG and Kessler MJ (1985) Climate and seasonal reproduction in the Cayo Santiago macaques American Journal of Primatology 9 87-99

Rawlins RG and Kessler MJ (1986) The history of the Cayo Santiago colony. In The Cayo Santiago Macaques, pp 13-45 Eds RG Rawlins and MJ Kessler. SUNY Press, Albany

Resko JA and Phoenix CH (1971) Sexual behavior and testosterone concentrations in the plasma of the rhesus monkey before and after castration Endocrinology 91 499-503 
Robinson JA, Scheffler G, Eisele SG and Goy RW (1975) Effects of age and season on sexual behavior and plasma testosterone and dihydrotestosterone concentrations of laboratory-housed male rhesus monkeys (Macaca mulatta) Biology of Reproduction 13 203-210

Rose RM, Bernstein IS, Gordon TP and Lindsley JG (1978) Changes in testosterone and behavior during adolescence in the male rhesus monkey Psychosomatic Medicine 40 60-70

Rose RM, Gordon TP and Bernstein IS (1972) Plasma testosterone levels in the male rhesus: influence of sexual and social stimuli Science 178 643-645

Ruehlmann TE, Bernstein IS, Gordon TP and Balcaen P (1988) Wounding patterns in three species of captive macaques American Journal of Primatology 14 125-134

Ruiz de Elvira M-C and Herndon JG (1986) Disruption of sexual behaviour by high ranking rhesus monkeys (Macaca mulatta) Behaviour 96 227-240

Sade DS (1964) Seasonal cycle in size of testes of free-ranging Macaca mulatta Folia Primatologica 2 171-180

Sade DS, Chepko-Sade BD, Schneider JM, Roberts SS and Richtsmeier JT (1985) Basic Demographic Observations on Free-ranging Rhesus Monkeys. Human Relations Area Files, New Haven

Sapolsky RM (1982) The endocrine stress-response and social status in the wild baboon Hormones and Behavior 16 279-292

Schenk PE and Slob AK (1986) Castration, sex steroids, and heterosexual behavior in adult male laboratory-housed stumptailed macaques (Macaca arctoides) Hormones and Behavior 20 336-353

Schwartz SM and Kemnitz JW (1992) Age- and gender-related changes in body size, adiposity, and endocrine and metabolic parameters in free-ranging rhesus macaques American Journal of Physical Anthropology 89 109-121

Sehgal A, David GFX, Dubey AK, Pruthi JS and Anand Kumar TC (1986) Circadian and circannual changes in the testicular function of adult rhesus monkeys Joumal of Bioscience 10 443-452

Smith DG, Rolfs B and Lorenz J (1992) A comparison of the success of electrophoretic methods and DNA fingerprinting for paternity testing in captive groups of rhesus macaques. In Paternity in Primates: Genetic Tests and Theories, pp 32-52 Eds RD Martin, AF Dixson and EJ Wickings. Karger, Base
Steiner RA and Bremner WJ (1981) Endocrine correlates of sexual development in the male monkey, Macaca fascicularis Endocrinology 109 914-919

Steklis HD, Brammer GL, Raleight MJ and McGuire MT (1985) Serum testosterone, male dominance and aggression in captive groups of male vervet monkeys (Cercopithecus aethiops sabaeus) Hormones and Behavior 19 154-163

Stonerook MJ and Harder JD (1992) Sexual maturation in female gray shorttailed opossums, Monodelphis domestica, is dependent upon male stimuli Biology of Reproduction 46 290-294

Turnquist JE and Kessler MJ (1989) Free-ranging Cayo Santiago rhesus monkeys (Macaca mulatta): I. Body size, proportions, and allometry American Journal of Primatology 19 1-13

Vandenbergh JG (1969a) Maie odor accelerates female sexual maturation in mice Endocrinology 94 658-660

Vandenbergh JG (1969b) Endocrine coordination in monkeys: male sexual responses to the female Physiology and Behavior 4 261-264

Watts ES (1990) Evolutionary trends in primate growth and development. In Primate Life History and Evolution, pp 89-104 Ed. J De Rousseau. Wiley-Liss, New York

Wickings EJ and Nieschlag E (1980) Seasonality in endocrine and exocrine testicular function of the adult rhesus monkey (Macaca mulatta) in a controlled laboratory environment International journal of Andrology 3 87-104

Wilkinson L (1988) SYSTAT: The System for Statisfics. Systat, Evanston

Wilson AP and Vessey SH (1968) Behavior of free-ranging castrated rhesus monkeys Folia Primatologica 9 1-14

Zamboni L, Conaway CH and Van Pelt L (1974) Seasonal changes in production of semen in free-ranging rhesus monkeys Biology of Reproduction 11 251-267

Ziegler TE, Savage A, Scheffler G and Snowdon CT (1987) The endocrinology of puberty and reproductive functioning in female cotton-top tamarins (Saguinus oedipus) under varying social conditions Biology of Reproduction 37 618-627

Ziegler TE, Snowdon CT and Uno H (1990) Social interactions and determinants of ovulation in tamarins (Saguinus). In Socioendocrinology of Primate Reproduction, pp 113-133 Eds TE Ziegler and FB Bercovitch. Wiley-Liss, New York 